\title{
Comorbid Depressive Disorders in ADHD: The Role of ADHD Severity, Subtypes and Familial Psychiatric Disorders
}

\author{
Michela Di Trani ${ }^{1}$, Francesca Di Roma², Andriola Elda ${ }^{3}$, Leone Daniela ${ }^{4}$, \\ Parisi Pasquale $^{5}$, Miano Silvia ${ }^{5}$, and Donfrancesco Renato ${ }^{6}$ \\ 1Department of Dynamic and Clinical Psychology, University of Rome Sapienza, Rome, Italy \\ 2U.O.N.P.I. Avezzano, L'Aquila, Italy \\ ${ }^{3}$ Humanitas-School of Cognitive Behavior Psychotherapy, Rome, Italy \\ ${ }^{4}$ Istituto di Neuropsichiatria Infantile, Università Cattolica del Sacro Cuore, Rome, Italy \\ ${ }^{5}$ DESMOS Department, Sant'Andrea Hospital, II Faculty of Medicine, University of Rome Sapienza, Rome, Italy \\ ${ }^{6}$ Pertini Hospital ASL RM/B, Rome, Italy
}

Objective To evaluate the presence of Major Depressive Disorder (MDD) and Dysthymic Disorder (DD) in a sample of Italian children with Attention Deficit Hyperactivity Disorder (ADHD) and to explore specific features of comorbid depressive disorders in ADHD.

Methods Three hundred and sixty-six consecutive, drug-naïve Caucasian Italian outpatients with ADHD were recruited and comorbid disorders were evaluated using DSM-IV-TR criteria. To evaluate ADHD severity, parents of all children filled out the ADHD Rating Scale. Thirty-seven children with comorbid MDD or DD were compared with 118 children with comorbid conduct disorder and 122 without comorbidity for age, sex, IQ level, family psychiatric history, and ADHD subtypes and severity.

Results 42 of the ADHD children displayed comorbid depressive disorders: 16 exhibited MDD, 21 DD, and 5 both MDD and DD. The frequency of hyperactive-impulsive subtypes was significantly lower in ADHD children with depressive disorders, than in those without any comorbidity. ADHD children with depressive disorders showed a higher number of familial psychiatric disorders and higher score in the Inattentive scale of the ADHD Rating Scale, than children without any comorbidity. No differences were found for age, sex and IQ level between the three groups.

Conclusion Consistent with previous studies in other countries, depressive disorders affect a significant proportion of ADHD children in Italy. Patient assessment and subsequent treatment should take into consideration the possible presence of this comorbidity, which could specifically increase the severity of ADHD attention problems.

Psychiatry Investig 2014;11(2):137-142

Key Words Attention deficit hyperactivity disorder, Depressive disorder, Comorbidity.

\section{INTRODUCTION}

Children with Attention Deficit Hyperactivity Disorder (ADHD) frequently have comorbid depressive disorders [Major Depressive Disorder (MDD) and Dysthymic Disorder (DD)]..$^{1-5}$ A national survey of the health of 61,779 children aged 6-17 years reported depression in $14 \%$ of $\mathrm{ADHD}$ children versus $1 \%$ of those without ADHD. ${ }^{6}$ Although the incidence of co-

Received: March 28, 2013 Revised: July 23, 2013

Accepted: September 12, 2013 Available online: April 11, 2014

$\triangle$ Correspondence: Michela Di Trani, PhD

Department of Dynamic and Clinical Psychology, University of Rome "Sapienza", Via dei Marsi 78, Rome 00185, Italy

Tel: +3906 49917989, Fax: +390649917903

E-mail: micheladitrani@hotmail.com

(a) This is an Open Access article distributed under the terms of the Creative Commons Attribution Non-Commercial License (http://creativecommons.org/licenses/by$\mathrm{nc} / 3.0$ ) which permits unrestricted non-commercial use, distribution, and reproduction in any medium, provided the original work is properly cited. morbidity ranges from $15 \%$ to $75 \%$, ADHD is more often associated with MDD than DD. ${ }^{7}$ According to one review of community studies, the incidence of depressive disorders in adolescents with ADHD ranges from $12 \%$ to $50 \%,{ }^{8}$ while Ambrosini et al. ${ }^{9}$ recently reported a comorbid diagnosis of minor depression/DD in $18.8 \%$ of children with ADHD. The increased rate of comorbid depression in adolescents with $\mathrm{AD}$ $\mathrm{HD}$ is not due to rater bias, but may be an epiphenomenal effect related to comorbid disorders that often occur in this population. ${ }^{10,11}$ However, at least one study has reported a higher rate of depression in children with ADHD than in those without $\mathrm{ADHD}$, regardless of other comorbidity. ${ }^{12}$

The correlation between ADHD subtypes and comorbid depression is not yet clear: several studies have shown that rates of depression do not differ between subtypes, ${ }^{13-15}$ while Ushijima $^{16}$ found a higher rate of depression in the ADHD 
combined subtype than in the ADHD inattentive subtype. Oner et al. ${ }^{17}$ found a higher Child Behavior Checklist Withdrawal Score ${ }^{18}$ in inattentive subtypes than in combined subtypes, while Acosta et al. ${ }^{19}$ found that depression levels were higher in both subtypes. Moreover, several studies have examined the link between ADHD, externalizing disorders and depression, Some of these studies consistently pointed to the stronger presence of depressive disorders in ADHD children when aggressive behavior, oppositional defiant disorder (ODD) or conduct disorder (CD) was also present. . $11,20,21^{2}$

What factors precede the development of depression? A study by Chronis-Tuscano et al. ${ }^{22}$ reported that the presence of depression in ADHD children is more evident in patients with maternal depression ${ }^{23}$ and in patients with concurrent emotional and behavioral problems from 4 to 6 years of age. Comorbid ADHD and depression may thus be characterized by a familial component. ${ }^{24}$ Indeed, Yang et al..$^{25}$ found a higher proportion of individuals affected by MDD among siblings of ADHD children than among controls.

Other studies have examined the role of sex as a potential risk factor for depression. Birmaher et al. ${ }^{26}$ reported a much stronger link between ADHD and depressive symptoms among girls than boys, and highlighted the frequent co-occurrence of anxiety symptoms. Girls with ADHD exhibited an earlier onset of depressive symptoms, higher hospitalization and suicide rates, as well as longer depressive episodes than girls with depression alone. ${ }^{27}$

The main aim of the present study was to evaluate clinically the presence of MDD and DD in a large sample of ADHD children; to the best of our knowledge, for the first time in Italy. Diagnosis of ADHD is relatively rare in Italy, therefore, the number of children who are treated with drugs for ADHD is small. It is consequently easy to enroll a large sample of children who have recently been diagnosed with ADHD and are still drug-naïve, thereby avoiding research bias. Moreover, in order to explore specific features of comorbid depressive disorders in ADHD, we selected children with only comorbid MDD and DD, excluding other comorbid conditions. Subsequently, we compared this group with ADHD children who exhibited comorbid conduct disorders and with those who did not have any comorbidity, on a range of variables that can be specifically linked to depressive disorders in ADHD children: age, sex, IQ level, family psychiatric history, and ADHD subtypes.

Finally, we investigated a possible correlation between the comorbidity of depressive disorders and severity of ADHD symptoms. As far as we are aware, this is the first time that such a correlation has been investigated.

\section{METHODS}

\section{Patients}

We studied 366 consecutive, drug-naïve Caucasian Italian outpatients with ADHD (321 male and 45 female; mean age: 105.15 months, SD: 30.26 ), diagnosed at a regional center for ADHD in Rome between January 2007 and December 2010. All the children underwent a diagnostic assessment based on the ADHD Rating Scale ${ }^{29}$ adapted for the Italian population, ${ }^{30}$ filled out by parents and school teachers. Both children and parents separately underwent a semistructured psychiatric interview, the Schedule for Affective Disorders and Schizophrenia for School-Age Children-Present and Lifetime Version (KSADS-PL), ${ }^{31}$ performed by the same experienced child psychiatrist (R.D.). Depressive disorders (MDD and DD) and CDs were referred to the categorical diagnosis generated by using K-SADS-PL. All the children were assessed by the Wechsler Intelligence Scale for Children III (WISC III, Italian version), ${ }^{32}$ and patients with IQ $<70$ were excluded. Socioeconomic status $^{33}$ was measured using the 3-point Hollingshead scale. A detailed personal and family history was obtained for each patient. All the psychiatric diagnoses were made according to DSM IV-TR. ${ }^{34}$ The assessment of familial psychiatric disorders was based on a careful anamnestic history obtained from both parents.

\section{Statistical analysis}

Differences in sociodemographic characteristics (age, sex, and socioeconomic level) were evaluated in all three groups (ADHD with comorbid depressive disorders, ADHD with comorbid CDs, and ADHD without comorbid disorders) by means of $\chi^{2}$ analysis of categorical variables and one-way ANOVA of continuous variables. To assess intergroup differences in IQ level and ADHD symptom severity, one-way ANOVA was also performed on the ADHD Rating Scale-PV scores and Total, Verbal and Performance IQ scores. Subsequently, Bonferronis post hoc test was performed to assess any specific differences between groups. In addition, $\chi^{2}$ analysis was performed to verify the distribution of ADHD subtypes (combined, hyperactive and inattentive) and the presence/absence of familiar psychiatric disorders in the three groups. Lastly, logistic regression was used to verify the predictive role of the demographic variables, $\mathrm{ADHD}$ severity and $\mathrm{ADHD}$ subtypes on the presence/absence of comorbid depressive or conduct disorders, which were codified as dummy variables. In particular, in different sets of analyses, the presence/absence of a comorbid depressive disorder and presence/absence of a comorbid conduct disorder were included as dependent variables and two models were run. The first included age, sex, socioeconomic level, IQ and ADHD Rating Scale-PV scores (Hyperactive and 
Inattentive scores) as independent variables, while the second model included age, sex, socioeconomic level, IQ and ADHD subtypes (combined, hyperactive and inattentive) as independent variables.

\section{RESULTS}

In our sample of 366 children with a diagnosis of ADHD, 42 (11.47\%) displayed comorbid depressive disorders: 16 (4.37\%) had only MDD, 21 (5.74\%) only had DD, and 5 (1.36\%) had both MDD and DD.

In order to evaluate the ADHD children with a specific comorbid depressive disorder, we selected 37 participants (16 MDD and 21 DD) and compared them with 118 children with a comorbid CD and 122 without any comorbidity. Eightyfour ADHD children with other comorbid disorders (17 with anxiety disorders, 12 with bipolar disorder, and 55 with learning disorders) were excluded from data analysis.

As Table 1 shows, no differences in age, socioeconomic level and sex distribution emerged between ADHD patients with depressive disorders, those with CDs, and those without any comorbid disorders.

Although no differences were found between the three ADHD groups for IQ levels ( $p$ always $>0.1$ ), differences emerged in the severity of ADHD, as shown by the ADHD Rating Scale-PV. Significant differences were found in the total $(\mathrm{F}=7.59 ; \mathrm{p}=0.001)$, hyperactivity $(\mathrm{F}=12.03 ; \mathrm{p}=0.000)$ and inat- tentive $(\mathrm{F}=4.52 ; \mathrm{p}=0.012)$ scales between the groups (Table 2$)$.

In particular, post-hoc analysis showed that: 1) children with comorbid CDs scored higher in the total scale than those without comorbidity $(\mathrm{F}=3.61 ; \mathrm{p}=0.050) ; 2)$ children with comorbid CDs scored higher in the hyperactivity scale than either children with depressive disorders $(\mathrm{F}=2.24 ; \mathrm{p}=0.050)$ or those without any comorbidity $(\mathrm{F}=2.63 ; \mathrm{p}=0.050) ; 3)$ children with depressive disorders scored higher in the inattentive scale than those without any comorbidity $(\mathrm{F}=2.39 ; \mathrm{p}=0.050)$.

As regards the ADHD subtype distribution, 18 (48.65\%) children with depressive disorder presented with the combined subtype, two (5.41\%) with the hyperactive-impulsive subtype, and 17 (45.94\%) with the inattentive subtype. Sixtynine $(58.48 \%)$ children with CDs presented with the combined subtype, $14(11.86 \%)$ with the hyperactive-impulsive subtype, and $35(29.66 \%)$ with the inattentive subtype. Forty-seven (38.52\%) of the ADHD children without comorbidity presented with the combined subtype, 23 (18.86\%) with the hyperactive-impulsive subtype, and $52(42.62 \%)$ with the inattentive subtype.

The frequency of hyperactive-impulsive subtypes was significantly lower in ADHD children with depressive disorders than in those without any comorbidity $\left(\chi^{2}=3.87 ; \mathrm{p}=0.049\right)$. The frequency of the combined subtype was significantly higher in ADHD children with CDs than in those without any comorbidity $\left(X^{2}=9.56 ; p=0.002\right)$. Finally, the frequency of the inattentive subtype was significantly lower in ADHD children

Table 1. Demographic data

\begin{tabular}{|c|c|c|c|c|c|}
\hline & $\begin{array}{c}\text { ADHD with } \\
\text { depressive disorders }\end{array}$ & $\begin{array}{c}\text { ADHD with } \\
\text { conduct disorder }\end{array}$ & $\begin{array}{l}\text { ADHD without } \\
\text { comorbidity }\end{array}$ & $\chi^{2} / F$ & $\mathrm{p}$ \\
\hline & $\mathrm{N}=37$ & $\mathrm{~N}=118$ & $\mathrm{~N}=122$ & & \\
\hline Boys & 33 & 105 & 102 & 2.17 & NS \\
\hline Age $(\mathrm{M}, \mathrm{SD})$ & $9.31,2.10$ & $8.75,2.51$ & $8.79,2.89$ & 0.66 & NS \\
\hline Socioeconomic status (M, SD) & $70.51,12.92$ & $74.18,14.15$ & $72.43,11.31$ & 1.31 & NS \\
\hline
\end{tabular}

ADHD: Attention Deficit Hyperactivity Disorder, M: mean, SD: standard deviation

Table 2. Comparison between the three groups on cognitive level and ADHD symptomatology

\begin{tabular}{|c|c|c|c|c|c|}
\hline & $\begin{array}{c}\text { ADHD with } \\
\text { depressive disorders }\end{array}$ & $\begin{array}{c}\text { ADHD with } \\
\text { conduct disorder }\end{array}$ & $\begin{array}{c}\text { ADHD without } \\
\text { comorbidity }\end{array}$ & $\mathrm{F} / \mathrm{X}^{2}$ & $\mathrm{p}$ \\
\hline & $\mathrm{N}=37$ & $\mathrm{~N}=118$ & $\mathrm{~N}=122$ & & \\
\hline Total IQ (M, SD) & $98.12,8.92$ & $101.56,15.26$ & $100.87,14.91$ & 0.80 & NS \\
\hline IQ-P & $96.27,12.64$ & $98.38,14.67$ & $97.42,14.84$ & 0.51 & NS \\
\hline IQ-V & $101.35,8.42$ & $104.18,14.39$ & $103.21,17.16$ & 0.33 & NS \\
\hline \multicolumn{6}{|l|}{ ADHD-RS (M, SD) } \\
\hline Total scale & $37.68,7.27$ & $38.61,7.57$ & $35.00,7.38$ & 7.59 & 0.001 \\
\hline Hyperactivity scale & $17.57,4.19$ & $19.81,4.18$ & $17.17,4.41$ & 12.03 & 0.000 \\
\hline Inattentive scale & $19.95,3.59$ & $18.72,4.77$ & $17.56,4.58$ & 4.52 & 0.012 \\
\hline
\end{tabular}

ADHD: Attention Deficit Hyperactivity Disorder, IQ: Intelligence Quotient, IQ-P: Intelligence Quotient-Performance, IQ-V: Intelligence Quotient-Verbal, M: mean, SD: standard deviation, ADHD-RS: Attention Deficit Hyperactivity Disorder-Rating Scale 
with CDs than in those without any comorbidity $\left(\chi^{2}=4.36\right.$; $\mathrm{p}=0.037$ ).

With regard to familial psychiatric disorders, 21 of the 122 children without any comorbidity (17.21\% comprising: $6.56 \%$ depressive disorders, $2.46 \%$ anxiety disorders, $2.46 \%$ bipolar disorder, and 5.73\% alcohol/substance dependence) had at least one parent with psychopathology compared with 13 of the 37 children with comorbid depressive disorders $(35.14 \%$ comprising: $16.21 \%$ depressive disorders, $10.81 \%$ anxiety disorders, $2.70 \%$ bipolar disorder, $2.70 \%$ alcohol/substance dependence, and $2.94 \%$ psychotic disorder) and 43 of the 118 children with conduct disorders (36.44\% comprising: 15.25\% depressive disorders, 5.08\% anxiety disorders, $4.24 \%$ bipolar disorder, 9.33\% alcohol/substance dependence, and 2.54\% psychotic disorder).

The analysis revealed a higher number of familial psychiatric disorders in ADHD children with depressive disorders $\left(\chi^{2}=5.42 ; \mathrm{p}=0.020\right)$ and $\operatorname{CDs}\left(\chi^{2}=11.34 ; \mathrm{p}=0.001\right)$ than in those without any comorbidity. No significant difference was found in familial psychiatric disorders between ADHD children with comorbid depressive disorders and those with CDs.

Lastly, logistic regression analysis revealed that the presence of comorbid depressive disorders in ADHD children was predicted by the hyperactivity $(B=-0.09, \mathrm{p}=0.045)$ and inattentive scores of the ADHD Rating Scale-PV $(B=0.13, p=$ 0.012). With regard to the presence of comorbid CDs, the data yielded two significant predictors: the hyperactivity score of the ADHD Rating Scale-PV $(B=0.17, \mathrm{p}=0.000)$ and, in a second set of analyses, the presence of the combined subtype $(\mathrm{B}=$ $0.84, \mathrm{p}=0.003)$.

\section{DISCUSSION}

The main aim of our study was to assess the presence of depressive comorbidity in ADHD children. A previous review reported an overall prevalence of depressive disorders in 12$50 \%$ of ADHD children, ${ }^{8}$ while a national survey of the health of 61,779 children reported depression in $14 \%$ of ADHD children. ${ }^{6}$ As regards DD, a recent study reported a comorbid diagnosis of minor depression/dysthymia in $18.8 \%$ of children with ADHD. ${ }^{9}$

In our sample of 366 children, 42 (11.47\%) of the participants displayed a comorbid depressive disorder: 16 (4.37\%) had MDD, 21 (5.74\%) had DD, and five (1.36\%) had both MDD and DD. The prevalence of depressive disorders in our sample appears to be lower than that reported in previous studies. ${ }^{6,89}$ The discrepancy between these estimates may be due to methodological issues. In particular, Larson et al. ${ }^{6}$ used parent reports to assess ADHD and other comorbid diagnosis: parents were asked whether a doctor had ever told them that their child had ADHD or other disorders. The diagnostic prevalence based on a parent report does not ensure the assessment of both the rate of false positives or negatives in the sample and of the original diagnosis (i.e., categorical or dimensional diagnosis). Moreover, Ambrosini et al. ${ }^{9}$ included minor depression and dysthymia in the same diagnostic group, without specifying the prevalence of DD alone. Lastly, our data are in agreement with the findings included in the review by Angold et al., ${ }^{8}$ who reported depression in about $13 \%$ of ADHD children. ${ }^{36,37}$

Future research should be aimed at confirming and clarifying the prevalence of depressive disorders in ADHD children. In order to obtain comparable data, attention should be paid to methodological aspects, such as the choice of informants, data collection, characteristics of the samples and diagnostic definition.

Moreover, the prevalence of DD comorbidity in our sample (5.74\%) was slightly higher than that of MDD (4.37\%), whereas Wilens et al. ${ }^{7}$ reported that ADHD is more often associated with MDD than with DD. This discrepancy may be attributable to cultural differences. In Italy, ADHD diagnosis is not as common as in other countries and methylphenidate was introduced in Italy in $2007 .{ }^{38}$ Clinical experience has often suggested that parents and teachers may be able interpret the typical behaviors of ADHD (hyperactivity and inattention) such as disobedience, and parents could be blamed because they fail to educate their children. ADHD children, therefore, could often be criticized and reprimanded. Moreover, even when ADHD is diagnosed, children in Italy, unlike those in other European countries, are inserted in standard classes, with specific educational courses not always being offered. ADHD children are thus exposed to comparisons with non-ADHD children and may consequently be stigmatized. Indeed, DD may, on account of its characteristic chronicity, be a consequence of a prolonged environmentally negative and hostile reaction toward ADHD symptoms.

In order to address the second aim of our study, which was to explore the specific features of a depressive diagnosis in ADHD, we compared three groups of ADHD children: those with only depressive comorbid disorders, only comorbid CDs, and without any comorbidity. No significant differences were found when sex, age, socioeconomic level and IQ of the different $\mathrm{ADHD}$ groups were compared. An association between comorbid disorders and ADHD severity was found, as assessed by means of the ADHD Rating Scale-PV: ADHD children with depressive disorders displayed higher scores in the inattentive scale, while ADHD children with CDs displayed higher scores in the hyperactive scale. The comorbidity of $\mathrm{ADHD}$ and depressive disorders increased the severity of attention problems, which is in keeping with the results of a pre- 
vious study. ${ }^{28}$ This may be explained by the presence of inattention symptoms in clinical depression, which may increase the inattentive features that are typical of ADHD children.

Data from ANOVA were confirmed by regression analysis, which revealed that higher hyperactivity and inattentive scores in the ADHD Rating Scale-PV predicted the presence of depressive disorders. As regards the ADHD subtypes, the hyperactive subtype in our study was less frequent in children with depressive comorbidity than in those without comorbidity, while the inattentive subtype was less frequent in children with $\mathrm{CD}$ comorbidity. The fact that the findings of previous studies regarding this topic are conflicting may be due to methodological issues such as the definition of depression, which may be defined by categorical diagnosis or by a questionnaire designed to determine the presence of depressive symptoms. Further studies aimed at assessing comorbid depressive disorders in ADHD subtypes are warranted to clarify this controversial topic.

With regard to family history, the analysis revealed a higher number of familial psychiatric disorders in ADHD children with both depressive and conduct disorders than in children without comorbidity. This may be considered the most original finding of this study because the findings of previous studies have shed light on other issues, such as the familial link between ADHD and depression, ${ }^{24}$ the increased likelihood of siblings of probands with ADHD of developing ADHD, and the higher prevalence of psychiatric comorbidity among affected siblings than healthy school children. ${ }^{25}$ Other studies have revealed that the co-occurrence of psychiatric disorders is more likely in children with ADHD and bipolar disorder than in those without. ${ }^{35}$

This study had some limitations. First, we evaluated a clinical and not a community-based sample, which means that only serious cases were taken into consideration, that is, those most likely to come to the attention of health services. Second, the sample was collected in a single city in central Italy. A wider catchment area that included rural areas and was not limited to one city such as Rome would have lent more weight to our findings. Lastly, our study did not, despite the large number of patients, clarify whether $\mathrm{CD}$ is a risk factor for depressive disorders.

Taken as a whole, our results with Italian drug-naïve children with ADHD are similar to those reported in other countries and to those in children treated medically, with the exception of the distribution of comorbidity in different subtypes of ADHD.

\section{REFERENCES}

1. Jensen JB, Burke N, Garfinkel BD. Depression and symptoms of attention deficit disorder with hyperactivity. J Am Acad Child Adolesc Psy- chiatry 1988;27:742-747.

2. Pliszka SR. Comorbidity of attention-deficit/hyperactivity disorder with psychiatric disorder: an overview. J Clin Psychiatry 1998;59(Suppl 7):50-58.

3. Spencer T, Biederman J, Wilens T. Attention-deficit/hyperactivity disorder and co-morbidity. Pediatr Clin North Am 1999;46:915-927.

4. LeBlanc N, Morin D. Depressive symptoms and associated factors in children with attention deficit hyperactivity disorder. J Child Adolesc Psychiatr Nurs 2004;17:49-55.

5. Lavigne JV, Lebailly SA, Hopkins J, Gouze KR, Binns HJ. The prevalence of ADHD, ODD, depression, and anxiety in a community sample of 4-year-olds. J Clin Child Adolesc Psychol 2009;38:315-328.

6. Larson K, Russ SA, Kahn RS, Halfon N. Patterns of comorbidity, functioning, and service use for US children with ADHD, 2007. Pediatrics 2011;127:462-470.

7. Wilens TE, Biederman J, Brown S, Tanguay S, Monuteaux MC, Blake $\mathrm{C}$, et al. Psychiatric comorbidity and functioning in clinically referred preschool children and schoolage youths with ADHD. J Am Acad Child Adolesc Psychiatry 2002;41:262-268.

8. Angold A, Costello EJ, Erkanli A. Comorbidity. J Child Psychol Psychiatry 1999;40:57-87.

9. Ambrosini PJ, Bennett DS, Elia J. Attention deficit hyperactivity disorder characteristics: II. Clinical correlates of irritable mood. J Affect Disord 2013;145:70-76.

10. Burke JD, Loeber R, Lahey BB, Rathouz PJ. Developmental transitions among affective and behavioral disorders in adolescent boys. J Child Psychol Psychiatry 2005;46:1200-1210.

11. Daviss WB. A review of co-morbid depression in pediatric ADHD: etiologies, phenomenology, and treatment. J Child Adolesc Psychopharmacol 2008; 18:565-571.

12. Blackman GL, Ostrander R, Herman KC. Children with ADHD and depression: a multisource, multimethod assessment of clinical, social, and academic functioning. J Atten Disord 2005;8:195-207.

13. Cantwell DP, Baker L. Attention deficit disorder with and without hyperactivity: a review and comparison of matched groups. J Am Acad Child Adolesc Psychiatry 1992;31:432-438.

14. Mayes SD, Calhoun SL, Chase GA, Mink DM, Stagg RE. ADHD subtypes and co-occurring anxiety, depression, and oppositional-defiant disorder: differences in Gordon diagnostic system and Wechsler working memory and processing speed index scores. J Atten Disord 2009; 12:540-550.

15. Nelson JM, Gregg N. Depression and anxiety among transitioning adolescents and college students with ADHD, dyslexia, or comorbid ADHD/ dyslexia. J Atten Disord 2012;16:244-254.

16. Ushijima H, Usami M, Saito K, Kodaira M, Ikeda M. Time course of the development of depressive mood and oppositional defiant behavior among boys with attention deficit hyperactivity disorder: differences between subtypes. Psychiatry Clin Neurosci 2012;66:285-291.

17. Oner O, Oner P, Cop E, Munir KM. Characteristics of DSM-IV attention deficit hyperactivity disorder combined and predominantly inattentive subtypes in a Turkish clinical sample. Child Psychiatry Hum Dev 2012;43:523-532.

18. Achembach TM. Manual for the Child Behavior Checklist 4-18 and 1991 Profiles. Burlington: University of Vermont, Department of Psychiatry; 1991.

19. Acosta MT, Castellanos FX, Bolton KL, Balog JZ, Eagen P, Nee L, et al. Latent class subtyping of attention deficit/hyperactivity disorder and comorbid conditions. J Am Acad Child Adolesc Psychiatry 2008;47: 797-807.

20. Biederman J, Mick E, Faraone SV. Depression in attention deficit hyperactivity disorder (ADHD) children: "true" depression or demoralization? J Affect Disord 1998;47:113-122.

21. Ostrander R. Herman KC. Potential cognitive, parenting, and developmental mediators of the relationship between ADHD and depression. J Consult Clin Psychol 2006;74:89-98. 
22. Chronis-Tuscano A, Molina BS, Pelham WE, Applegate B, Dahlke A, Overmyer M, et al. Very early predictors of adolescent depression and suicide attempts in children with attention-deficit/hyperactivity disorder. Arch Gen Psychiatry 2010;67:1044-1051.

23. Harris K, Boots M, Talbot J, Vance A. Comparison of psychosocial correlates in primary school age children with attention deficit/ hyperactivity disorder- combined type, with and without dysthymic disorder. Child Psychiatry Hum Dev 2006;36:419-426.

24. Faraone SV, Biederman J. Do attention deficit hyperactivity disorder and major depression share familial risk factors? J Nerv Ment Dis 1997; 185:533-541.

25. Yang LK, Shang CY, Gau SS. Psychiatric comorbidities in adolescents with attention-deficit hyperactivity disorder and their siblings. Can J Psychiatry 2011;56:281-292.

26. Birmaher B, Ryan ND, Williamson DE, Brent DA, Kaufman J, Dahl $\mathrm{RE}$, et al. Childhood and adolescent depression: a review of the past 10 years Part I. J Am Acad Child Adolesc Psychiatry 1996;35:1427-1439.

27. Biederman J, Ball SW, Monuteaux MC, Mick E, Spencer TJ, McCreary $\mathrm{M}$, et al. New insights into the comorbidity between ADHD and major depression in adolescent and young adult females. J Am Acad Child Adolesc Psychiatry 2008;47:426-434.

28. Ulloa RE, Sánchez S, Sauceda JM, Ortiz S. Psychopathology associated to attention deficit hyperactivity disorder in school age children. Actas Esp Psiquiatri 2006;34:330-335.

29. DuPaul GJ, Power TJ, Anastopoulos AD. ADHD Rating Scale-IV. New
York: Guilford Publications; 1998

30. Marzocchi GM, Cornoldi C. An easy to use scale for the assessment of problematic behaviors in ADHD children. Psicol Clinic Sviluppo 2000;4:43-64.

31. Kaufman J, Birmaher B, Brent D, Rao U, Flynn C, Moreci P, et al. Schedule for Affective Disorders and Schizophrenia for School-Age Children-Present and Lifetime Version (K-SADS-PL): initial reliability and validity data. J Am Acad Child Adolesc Psychiatry 1997;36:980-988.

32. Orsini A, Picone L. Contributo alla taratura italiana di Wechsler Intelligence Scale for Children (WISC-III). Firenze: Giunti OS; 2006.

33. Hollingshead A. Four Factor Index of Social Status. New Haven: Yale University Department of Sociology; 1957.

34. American Psychiatric Association. Diagnostic and Statistical Manual of Mental Disorders, 4th Edition. Text Revision. Washington DC: American Psychiatric Association; 2000.

35. Donfrancesco R, Miano S, Martines F, Ferrante L, Melegari MG, Masi G. Bipolar disorder co-morbidity in children with attention deficit hyperactivity disorder. Psychiatry Res 2011;186:333-337.

36. Angold A, Costello EJ, Farmer EM, Burns BJ, Erkanli A. Impaired but undiagnosed. J Am Acad Child Adolesc Psychiatry 1999;38:129-137.

37. Velez CN, Jonhnson J, Cohen P. A longitudianal analysis of selected risk factors of childhood psychopathology. J Am Ac Child Adolesc Psychiatry 1989;28:861-864.

38. Official Gazette of the Italian Republic 2007;106:5-54. 